\title{
Train Wheels Eigenmodes on Effects of Vibration and Track Deterioration in the Belfast to Steelpoort Railway Line
}

\author{
Bingo Balekwa*1, Daramy Vandi Von Kallon ${ }^{1}$ \\ ${ }^{1}$ Department of Mechanical and Industrial Engineering Technology, University of Johannesburg, \\ Level 7, John Orr Building, 47 Nind Street, Doornfontein, Johannesburg, 2092, South Africa,
}

\begin{abstract}
In South Africa, one of the main lines situated in its Limpopo Province presents symptoms of excessive vehicle-track vibrations. A modal method is adopted to study the difference in dynamic response of corrugated rails resting on the Hytrel/6385 and High Density Polyethylene (HDPE) rail pads. The results for dynamic response of rails on these two types of rail pads are analysed in form of Frequency Response Functions (FRFs). Two positions are considered in obtaining these point FRFs; those are mid-span and on top of sleeper. Resonance modes of significance are excited in a frequency range of $0-500 \mathrm{~Hz}$ on rails resting on both types of rail pads. In view of the entire vibration response window, the FRFs show a more damped vibration response by rail resting on the HDPE than that resting on the Hytrel/6358 rail pad. A Finite Element (FE) modal analysis method is used to investigate vibration mode shapes and corresponding frequencies of the wheelset used by the locomotive operating in the line. In the high frequency range of $350-500 \mathrm{~Hz}$, the gear-side wheel of a locomotive wheelset proves to be vibrating more erratically than the non-gear side wheel. Clearly pronounced mode shape excited at a frequency of $350 \mathrm{~Hz}$ and higher are presented.
\end{abstract}

\section{Introduction}

Rail corrugation is a damage that forms on the running surface of the rail due to dynamic of the wheel-rail system. Short-pitch corrugation on the inner rail of track curves in the railway line from Belfast to Steelpoort drew interest in the current research [1]. Rail corrugation is considered a global enigma in the railway space and has been pursued for over a century [2]. This problem also forms in metro and high speed systems [3-4]. High speed systems are generally associated with higher frequencies of vibration, mostly beyond $1 \mathrm{kHz}$ [5]. In some environments corrugation can form on railway wheel threads and is referred to as wheel polygonisation [6]. Causes of rail corrugation formation may differ per environment, but it is understood from the literature to form due to the damage mechanism and fixed on rails by wavelength fixing mechanisms [7]. Currently there is no primary cure for rail corrugation and rail grinding remains the common treatment [8-9]. Researchers in the recent years are developing methods to detect, identify and study rail corrugation through computer vision [10-12]. People who live closer to affected railway sites are exposed to mechanical vibrations that may negatively impact on their well-being. Figure 1. shows rail corrugation captured at one of the track curves in the railway line of concern.

\footnotetext{
* Corresponding author: bingo.balekwa@yahoo.com
} 


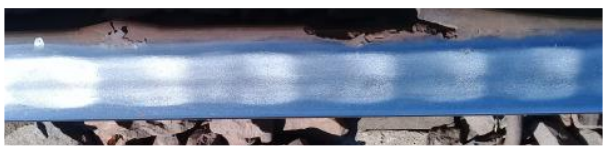

Fig. 1. Rail corrugation on the low rail of one of the monitored track curves.

A periodic wavelength average of $80-90 \mathrm{~mm}$ was measured [1]. Together with train speeds, this average wavelength per corrugated track curve was used to calculate the "corrugation frequency" for track curves. After which the resonance frequencies of a wheelset used by a D39200 locomotive were measured using the modal method. The results showed reasonable agreement of correlation of the corrugation frequencies, with resonance frequencies of the wheelset on track curves. It was established that a stronger correlation occurs at $108 \mathrm{~Hz}$. Rail resonance modes were not considered in the previous investigation [13-14]. The current study focuses on a high frequency wheel-rail resonance modes. It also focuses mainly on the dynamic differences between the responses of rails resting on two types of rail pads i.e. HDPE and Hytrel/6358. Rail response to vibration excitation was measured in the vertical and horizontal directions. Figures $2 \mathrm{a}$ and $2 \mathrm{~b}$. show the HDPE and the Hytrel/6358 rail pads. The HDPE rail pad (Figure. 2a) is used on the FY-type concrete sleeper. The Hytrel rail pad is used on the PY-type concrete sleepers.

(a)

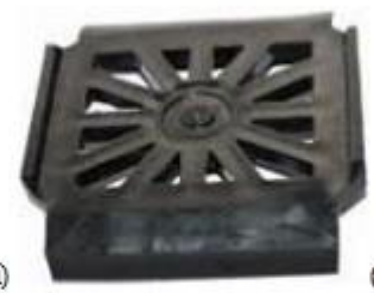

(b)

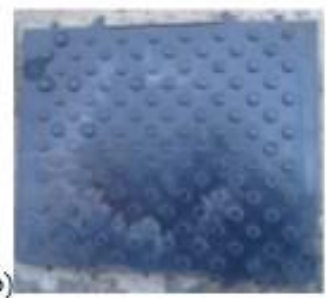

Fig. 2. (a) HDPE rail pad used on the FY-type concrete sleeper (b) Hytrel/6358 rail pad used on the PY-type concrete sleepers.

The design of the FY-type concrete sleeper restricts the horizontal displacement of the pad. The Hytrel/6358 is designed with studs on both sides of the pad. Figure 3. illustrates the arrangement of three studs along the cross section of a rail pad.

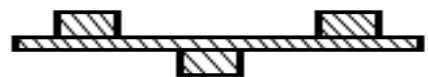

Fig. 3. Cross section of three studs arranged on the two opposite faces of the Hytrel/6358 rail pad.

Rail pads protect sleepers against impact and wear, ensure resiliency during vibration, ensures a higher creep resistance and provides electrical resistance [15]. In his illustration, Thompson [16] considered the dynamic difference of rail pads with a difference in stiffness. Figure 4. shows the illustration.
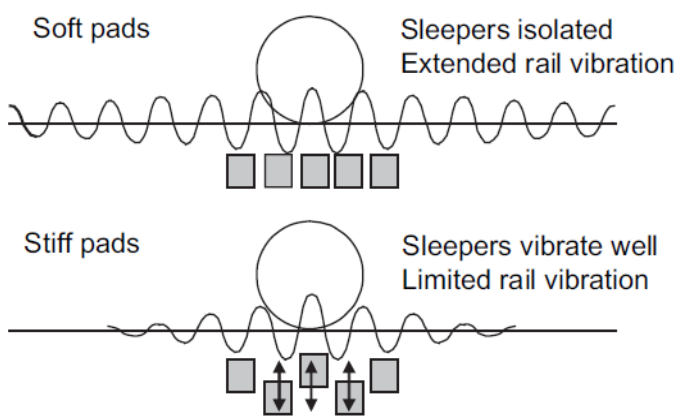

Fig. 4. Illustration of the effect of a rail pad stiffness on the rail and sleeper coupling; and on the damping of vibration waves in the rail [16]. 
Evident in Figure 4. is that for softer rail pads, vibration of the rail is isolated from that of sleepers but propagation of vibration can happen freely along the rail. Contrary to this, for stiffer pads, vibration by the rail is constrained by the fastening system and damping of the pads, ultimately causing a shorter rail length to vibrate. The rail pad stiffness significantly affects rail vibration damping and the amount of coupling between rail sleepers [16]. In general the damping of a wheel is higher than that of a track structure, however, this does not significantly affect the point FRF of the track structure at $500-1000 \mathrm{~Hz}$ [16]. Nonetheless, the importance of damping introduced through the track structure is given that it has an influence on vibration decay rate along the rail track [16]. In the recent work a wavelength fixing mechanism for short pitch rail corrugation is established [17-18].

\subsection{Effects of Rail Corrugation-Borne Vibration}

Damages attributed to excessive vibrations were noted during in the Belfast to Steelpoort railway line. Figure 5a. shows the damage on rail pads due to excessive vibration and Figure 5 b. shows the effect of the damage on rail pads. The rail ultimately makes direct contact with the concrete sleeper, ultimately exposes a sleeper to high dynamic loads and creepage. The clamping force of the fastening system is understood to be adequate when every component is at its right place, hence once the rail pad breaks or find its way out of the system there is no more sufficient clamping, this ultimately causes loosening of the fastening system at its entirety and dislocation of its components. is no more sufficient clamping, this ultimately causes loosening of the fastening system at its entirety and dislocation of its components.

(a)
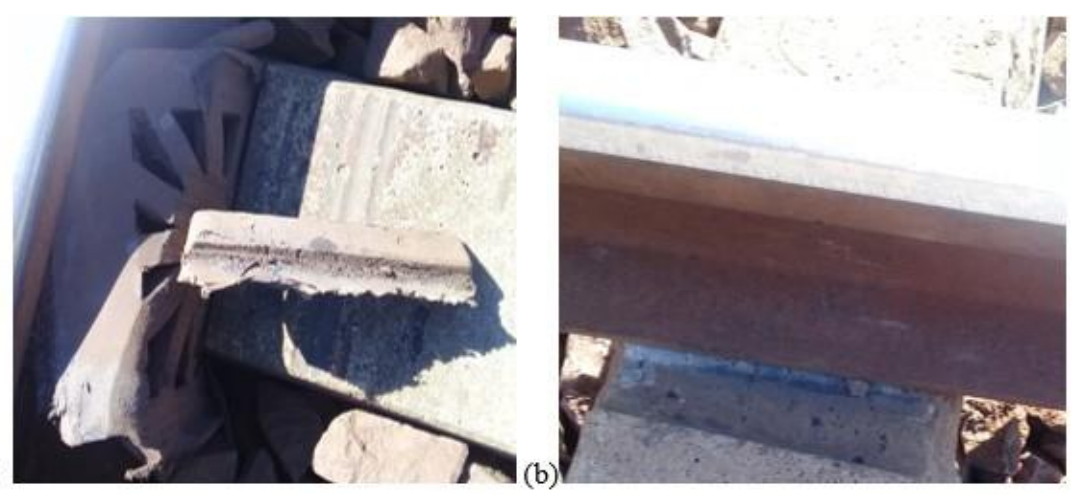

Fig. 5. (a) Rail pad damage (b) effect of rail pads damage due to excessive vibration.

Figure 6. shows deteriorated ballast quality due to excessive rail track vibration.

(a)

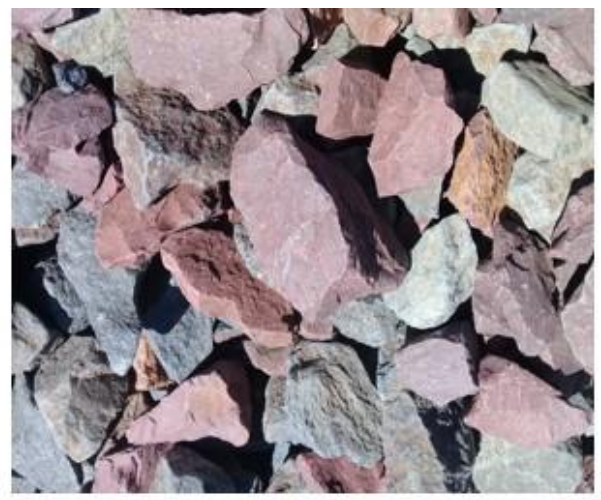

(b)

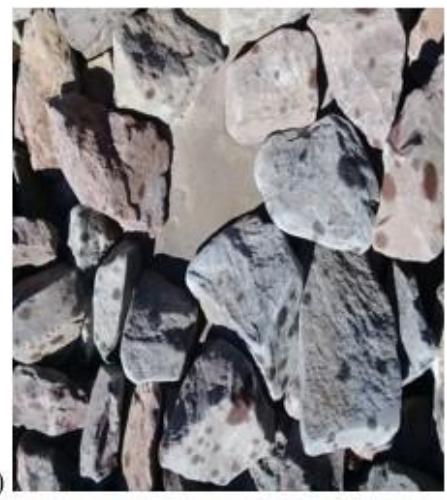

Fig. 6. (a) Desirable ballast condition (b) undesirable ballast condition. 
Other functions of the ballast in a track are to bear the load from the sleepers and provide horizontal stability to the track [19-20]. For the ballast to perform this function well, friction should be adequate between surfaces of the ballast rocks, to prevent ease of ballast settlement. Figure 6a. shows a new, desirable condition of a ballast for an ideal rail track and Figure $6 \mathrm{~b}$. an old undesirable condition. Under the ballast condition in Figure 6b. the ballast rocks may easily displace, leaving the sleepers exposed as seen in Figure 7a.

(a)

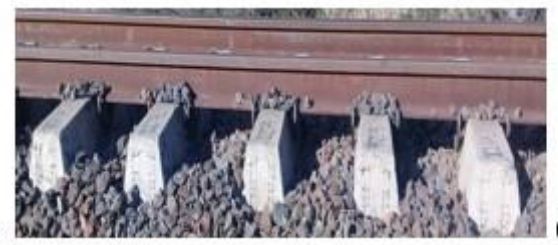

(b)

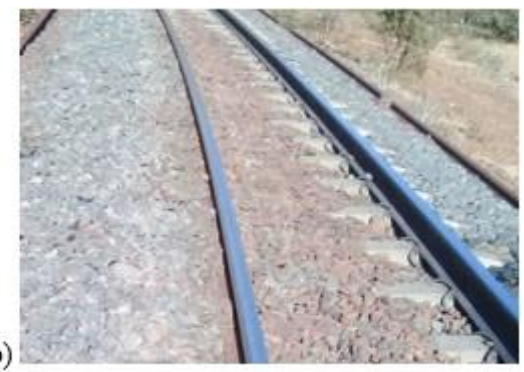

Fig. 7. (a) Excessively exposed concrete sleepers (b) Concrete sleepers adequately covered by ballast.

Figure $7 \mathrm{~b}$. shows the adequately ballasted part of the track where concrete sleepers are not excessively exposed. Exposed sleepers (as seen in Figure 7a.) can vibrate the most and for a longer period with lack of ballast friction to damp the energy.

\section{Method}

Two methods are used in the study i.e. the experimental and FEA modal analysis methods.

\subsection{Setup for Experimental Modal Analysis on Rails}

Rail vibration is excited using an impact hammer. The response is measured in the vertical and horizontal directions using an accelerometer placed on the field side of the rail crown as seen in Figure 8. The equipment utilised to supply power for the experiment was the battery bank, Uninterrupted Power Supply (UPS), power generator, Signal Express software (to compute measured FRFs), National Instruments PXi (hardware in which the computing software is installed). Rails were first cleaned using a pencil grinder and some chemicals for preparation of modal testing. Two test sites were used for modal analysis on rails; the track curves installed with the FY and PY-types of concrete sleepers. These are respectively situated at kilometer points $181 / 6$ and $187 / 13$ in the rail track. Figure 8 shows a prepared rail and an accelerometer placed on the crown for modal testing. The test site in Figure 8. installed with the FY-type concrete sleepers.

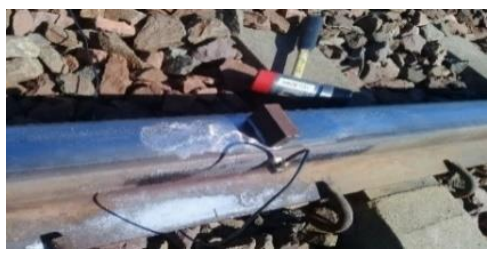

Fig. 8. Impact hammer, accelerometer and surface preparation for experiment on rail resting on FYtype concrete sleepers.

The rail is clamped on the FY-type concrete sleepers using the FISTclip fastening system. The impact hammer used for the experiment is also shown in Figure 8. The rail resting on 
the PY-type concrete sleepers was cleaned following the same procedure. The e-Clip fastening system is used for clamping the rail onto pads and the PY-type concrete sleepers. Vertical vibration modes were excited by applying impacts downwards on the rail working surface. Horizontal modes were excited by applying impacts on the rail crown, in the field side. The accelerometer remained in a single position, whilst impacts were applied as close as possible (approximately $5 \mathrm{~mm}$ from the measuring point). Five excitation impacts were applied continuously to better define a single FRF in each direction. Three FRF measurements were taken in each direction to ensure accuracy and reporting of the most pronounced FRFs. Figure 9. shows an image of an e-Clip fastening system clamping the rail resting on the PY-type concrete sleeper.

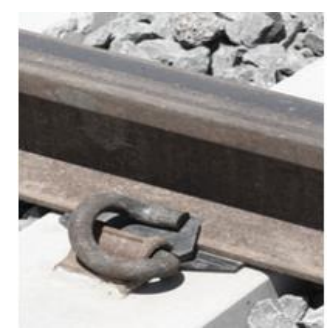

Fig. 9. Rail on PY-type concrete sleeper with an e-Clip fastening system.

The e-Clip fastening system uses components embedded on concrete sleepers to restrict displacement of the rail, pad and clips.

\subsection{Finite Element Modal Analysis Setup}

A 3D Finite Element Model (FEM) of the D39 200 locomotive traction wheelset was developed as shown in Figure 10.

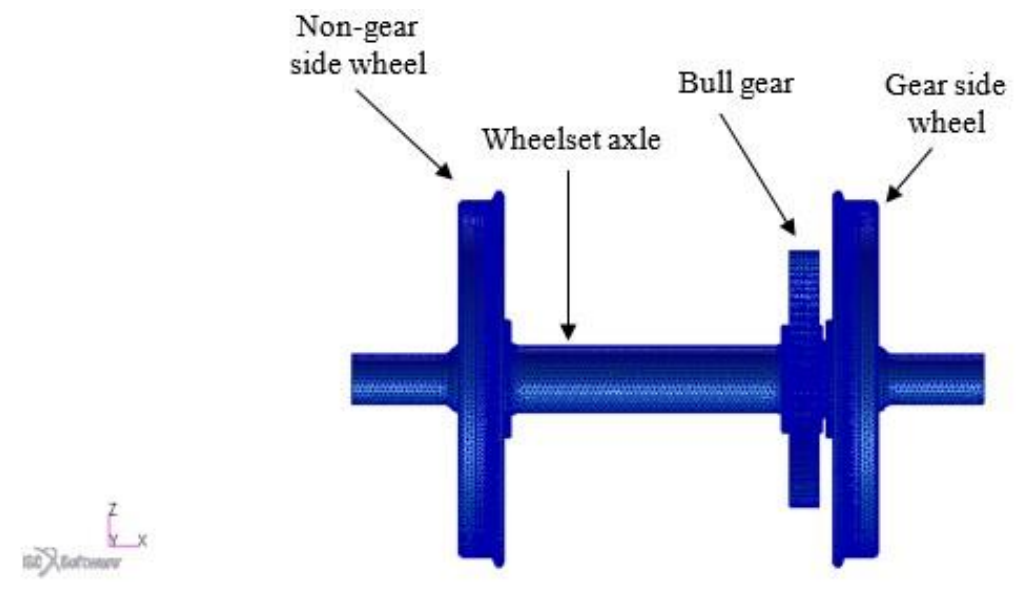

Fig. 10. FEA model for a D39200 locomotive traction wheelset.

The traction wheelset model in Figure 10. includes a bull gear mounted on a wheelset axle. The bull gear was modelled to accurate dimensions with teeth profile. The coupling between the bull gear and traction motor pinion is not modelled. The gear case is also not modelled. The mesh details for the FEM are tabulated in Table 1. 
Table 1. Mesh details for the traction wheelset FEM.

\begin{tabular}{|c|c|}
\hline Mesh Item & Mesh Details \\
\hline Mesh type & Solid \\
\hline Element type & Tetrahedron \\
\hline Mesher & TetMesh \\
\hline Topology & Tet 10 \\
\hline
\end{tabular}

Tet10 solid elements were used on all solids of the wheelset model to ensure better contact definition. The element nodes were equivalenced to $0.1 \mathrm{~mm}$ to ensure better alignment of the nodes on created contacts, and also to get rid of unnecessary nodes in the model. The element nodes were equivalenced to $0.1 \mathrm{~mm}$ to ensure better alignment of the nodes on created contacts, and also to get rid of unnecessary nodes in the model. Table 2 shows mesh convergence for the wheelset model. Mesh convergence was measured on the first bending mode only, for all mesh sizes.

Table 2. Mesh convergence for wheelset model.

\begin{tabular}{|c|c|c|}
\hline $\begin{array}{c}\text { Element Global } \\
\text { Edge Length } \\
(\mathbf{m m})\end{array}$ & $\begin{array}{c}\text { Number of } \\
\text { Nodes }\end{array}$ & $\begin{array}{c}\text { Maximum } \\
\text { Displacement } \\
\text { (mm) }\end{array}$ \\
\hline 250 & 48,188 & 42.3 \\
\hline 50 & 182,346 & 43.8 \\
\hline 10 & 763,491 & 54.7 \\
\hline 5 & 823,157 & 57.3 \\
\hline 4 & 834,568 & 57.7 \\
\hline 3.5 & 869,498 & 58.1 \\
\hline 3 & 905,567 & 58.1 \\
\hline
\end{tabular}

Materials are understood to be isotropic and the material properties of steel used in the FEA model are tabulated in Table 3.

Table 3. Material properties of the traction wheelset FEA model.

\begin{tabular}{|l|l|l|l|}
\hline \multicolumn{1}{|c|}{ Material } & \multicolumn{1}{|c|}{$\begin{array}{c}\text { Young's } \\
\text { Modulus (GPa) }\end{array}$} & Density (kg/m3) & Poisson's Ratio \\
\hline Steel & 210 & 7850 & 0.3 \\
\hline
\end{tabular}

Constraints and loads were not applied in the model in all Degrees of Freedom (DoF). Vibration frequency is set to a range of $0-500 \mathrm{~Hz}$ to capture the vibration modes that correspond to a short pitch corrugation on rails. 
Vibration modes requested are sixteen, which include the first six rigid body modes. Hence the vibration mode number seven is in principle the first mode. The bull gear material properties used are the same as those of the entire wheelset.

\section{Results}

In the current study only the low vibration frequency range $(0-500 \mathrm{~Hz})$ is considered. Shortpitch rail corrugation found in the railway line between Belfast and Steelpoort corresponds to a low frequency range of vibration [1]. Furthermore, it is in a low frequency range that the horizontal vibration is predominantly transmitted downwards [21]. At higher frequencies the vibrations are understood to be transmitted along the rail. The stiffer the rail pad, the more vibration is transmitted downward to the sleepers [21-22]. This is in agreement with [16] as illustrated in Figure 4. Vibrations transmitted downwards to the sleepers are at their greatest around the antiresonance of the rail [21]. However in order to test this, FRFs from rail and sleepers would have to be tested simultaneously. The difference in the design of these two types of rail pads may play a role in allowing and or constraining horizontal vibration.

\subsection{Experimental Modal Analysis Results}

Modal analysis was conducted to investigate the difference in dynamics of rails resting on HDPE and Hytrel/6358 rubber rail pads. This was done to investigate how the rails respond to vibration excitation when resting on these two types of sleepers. Part of the ultimate aim of the study is to establish how these dynamics can be associated with existence of corrugation on rails. The data is presented in form of FRFs. Figure 11. shows vibration response of a rail in the vertical direction when the rail is excited on top of sleeper point and mid-span. Figure 12. shows vibration response of a rail in the horizontal direction when the rail is excited on top of sleeper point and mid-span.

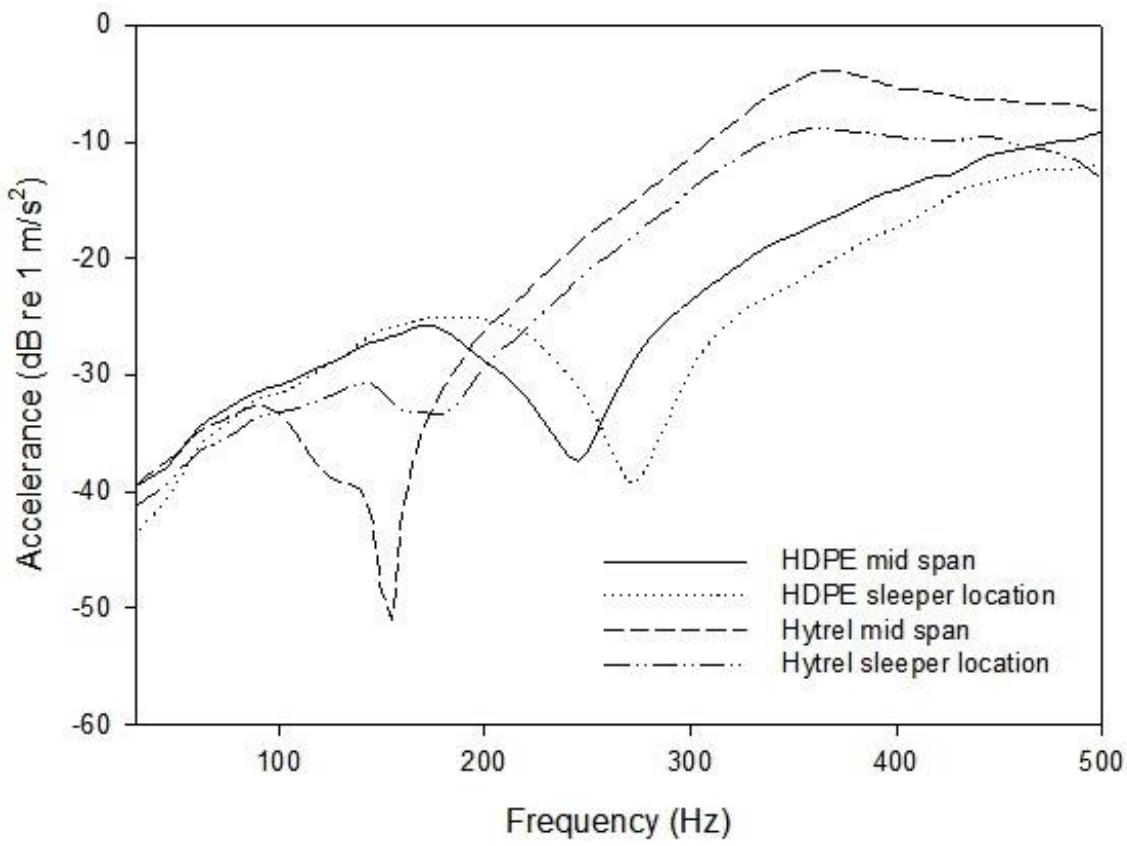

Fig. 11. Vibration response of rail resting on HDPE and Hytrel/6358 in the vertical direction. Rail is excited on two points - on top of sleeper point and mid-span. 


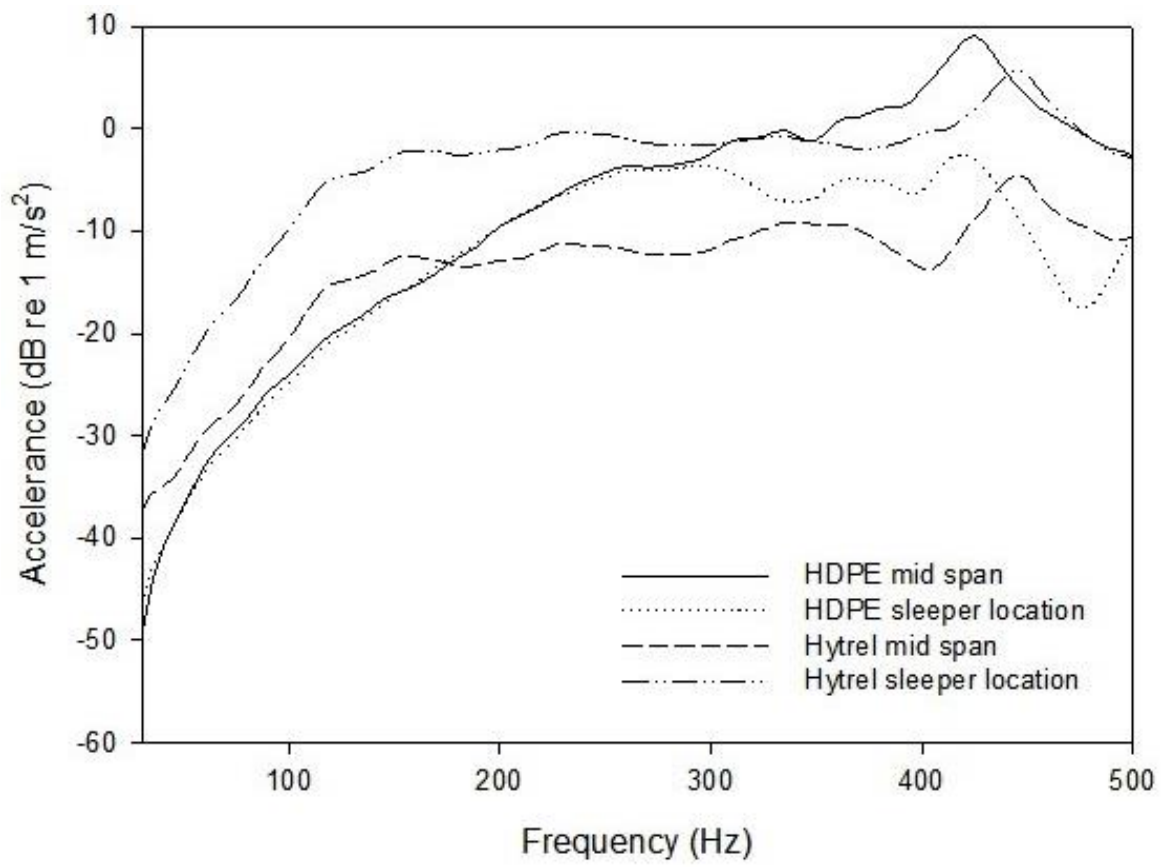

Fig. 12. Vibration response of rail resting on HDPE and Hytrel/6358 in the horizontal direction. Rail is excited on two points. On top of sleeper point and mid-span.

Seen in Figure 11. is that rails resting on both types of pads show a constant increase in vibration in the frequency range of $0-100 \mathrm{~Hz}$. In the previous study, rail corrugation fixed in the track curves of the railway line with which the current study is concerned showed evidence of development by D39200 locomotive class wheels at $108 \mathrm{~Hz}$. That frequency falls not far off from $100 \mathrm{~Hz}$ (where response of rail is in the rise in the horizontal direction). At $150 \mathrm{~Hz}$ the rail resting on a Hytrel/6358 pad vibrates with antiresonance when excited midspan. This is seen by a narrow ditch in the FRF representing an antiresonance by the rail.

No antiresonance vibration is experienced by the rail when the rail excitation impact is applied directly on the rail crown point that is direct with the rail pad. The rail resting on HDPE rail pads experienced antiresonance twice at low frequency vibration i.e. when the rail is excited either mid-span and or on the rail crown point that is direct with the rail pad. This antiresonance vibration occurs at a frequency range of about $250-300 \mathrm{~Hz}$. In the horizontal direction, on top of a sleeper position, the rail on HDPE pads responds with more accelerance (acceleration per unit force) for most of the vibration response in a low frequency rang. This may be because the rail is much stiffer on top of a sleeper than mid-span due to the clamping force applied by the fastening system. Both rails on HDPE and on Hytrel/6358 respond at resonance at a frequency range of $400-500 \mathrm{~Hz}$. Only heavily damped vibration modes are identified in the frequency range of $100-150 \mathrm{~Hz}$, which corresponds to a short-pitch rail corrugation frequency.

\subsection{FEA Modal Analysis Results}

Resonance modes in the high frequency range of $350-500 \mathrm{~Hz}$ are studied. Four resonance modes are captured with their shapes in the frequency range of $350-377 \mathrm{~Hz}$. Figures 13 to 16. show the mode shapes that occur at each resonance (in the high frequency range of 350 $-500 \mathrm{~Hz}$ ) during vibration. 
Patran 2019 11-Dec-19 19:07:11

Fringe: SC1:DEFAULT, A2:Mode 13: Freq. $=350.616$, Eigenvectors, Translational, Magnitude, (NON-LAYERED)

Deform: SC1:DEFAULT, A2:Mode 13: Freq. $=350.616$, Eigenvectors, Translational,

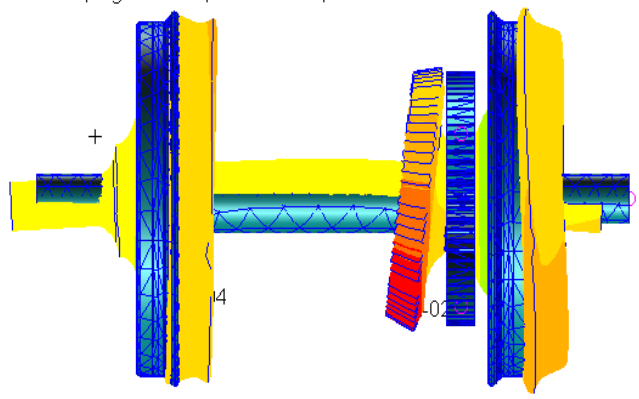

Fig. 13. Wheelset vibration mode shape $-350 \mathrm{~Hz}$

\section{Patran 2019 11-Dec-19 19:08:01}

Fringe: SC1:DEFAULT, A2:Mode 14: Freq. $=353.281$, Eigenvectors, Translational, Magnitude, (NON-LAYERED)

Deform: SC1:DEFAULT, A2:Mode 14: Freq.=353.281, Eigenvectors, Translational,
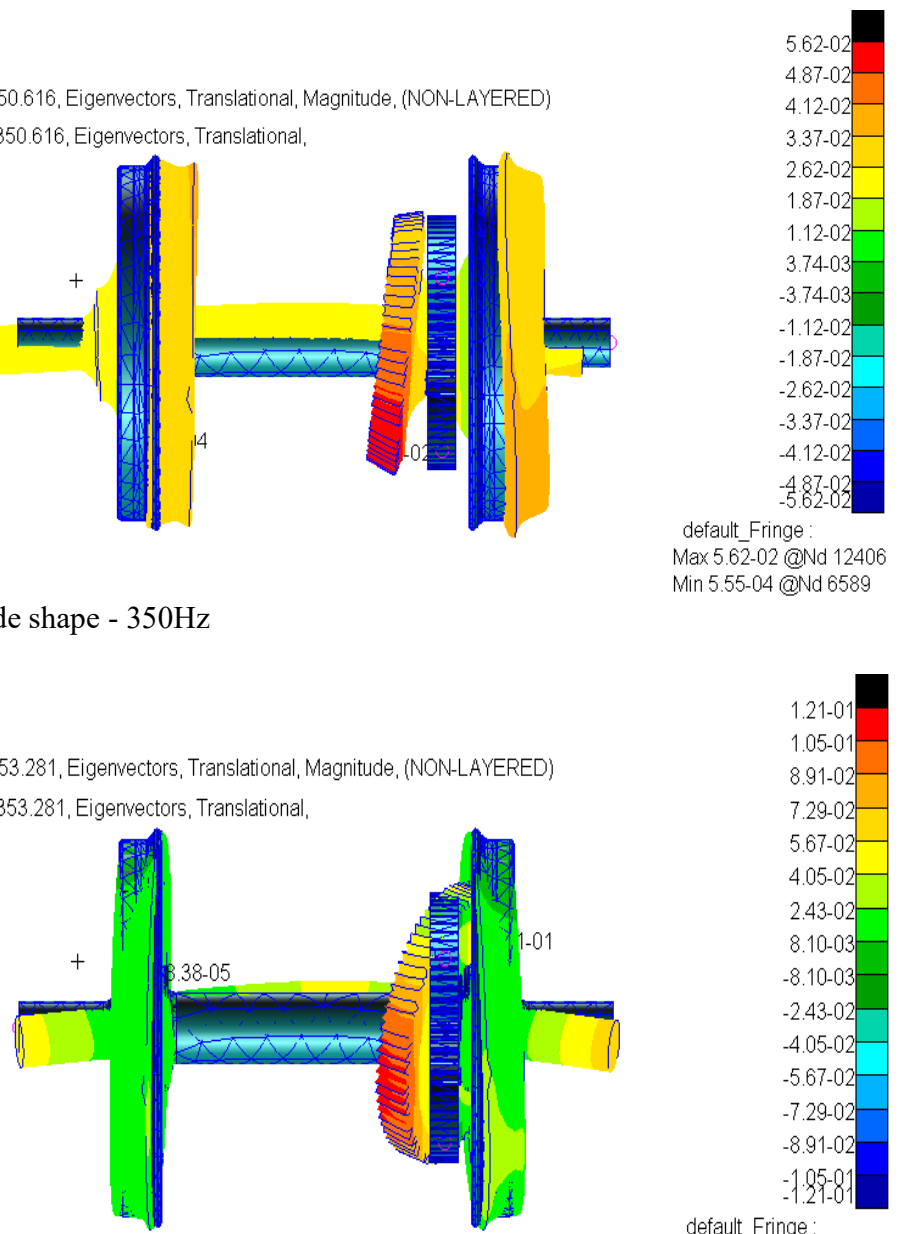

Min5.55-04@Nd6589

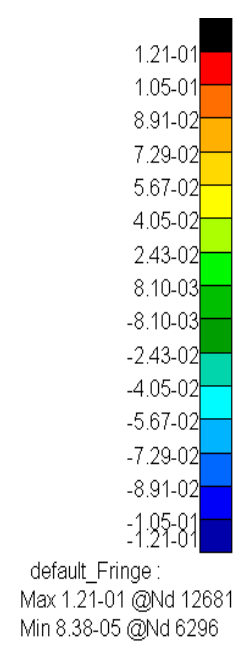

Fig. 14. Wheelset vibration mode shape $-353 \mathrm{~Hz}$ 
Patran 2019 11-Dec-19 19:08:43

Fringe: SC1:DEFAULT, A2:Mode 15: Freq. $=358.519$, Eigenvectors, Translational, Magnitude, (NON-LAYERED)

Deform: SC1:DEFAULT, A2:Mode 15: Freq. $=358.519$, Eigenvectors, Translational,

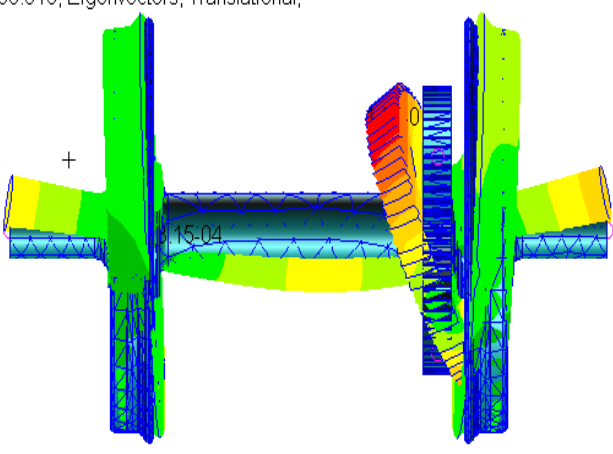

Fig. 15. Wheelset vibration mode shape $-358 \mathrm{~Hz}$

\section{Patran 2019 11-Dec-19 19:09:28}

Fringe: SC1:DEFAULT, A2:Mode 16: Freq. $=376.833$, Eigenvectors, Translational, Magnitude, (NON-LAYERED)

Deform: SC1:DEFAULT, A2:Mode 16: Freq. $=376.833$, Eigenvectors, Translational,
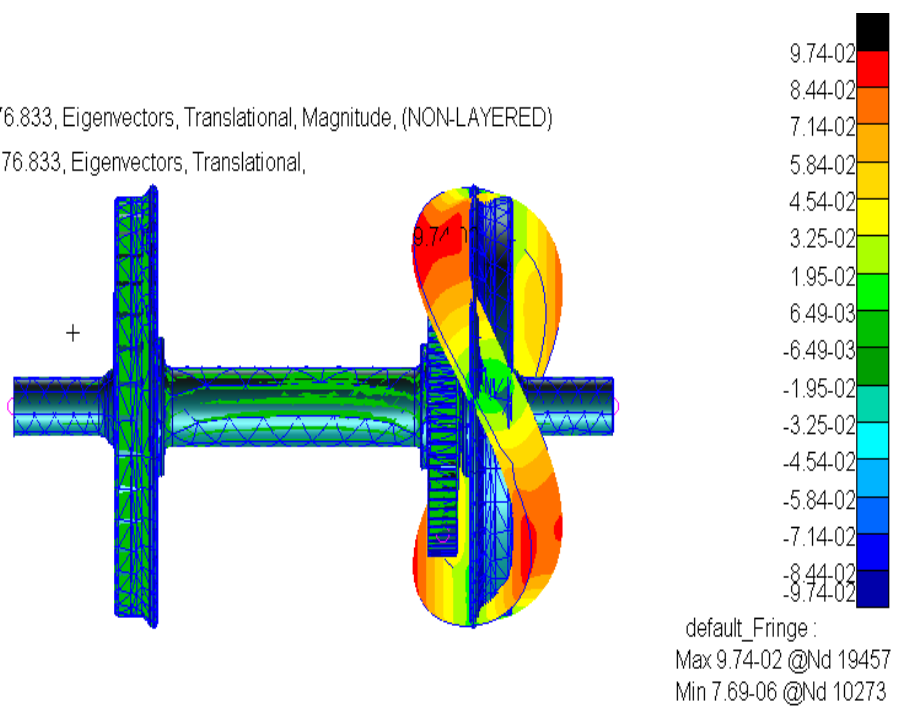

Fig. 16. Wheelset vibration mode shape $-376 \mathrm{~Hz}$

In Figures 13 to 16. the traction wheelset used by a D39200 locomotive class has a traction gear on one side of the axle. The two wheels of the wheelset are referred to as the gear and non-gear side wheels. Evident in Figures 13 to 16. is that for a selected frequency range of $350-500 \mathrm{~Hz}$ the wheels vibrate at resonance at frequencies $350 \mathrm{~Hz}, 353 \mathrm{~Hz}, 358 \mathrm{~Hz}$ and $376 \mathrm{~Hz}$. During vibration, in these resonance frequencies the gear side wheel proves to experience more erratical vibration than the non-gear side wheel. Only at a frequency of $350 \mathrm{~Hz}$ does the non-gear side wheel show erratical oscillation in the lateral direction as the axle mode is on bending. For a selected frequency range, the axle vibrates with a bending mode shape for all for vibration modes except for the resonance mode that occurs at $376 \mathrm{~Hz}$. Erratical vibration is also experienced by the traction gear, which is pressed onto the axle much closer to the gear side wheel. The vibration mode shapes of the wheels become more complicated as the vibration frequency increases. 


\section{Implications, Conclusions and Recommendations}

Rail pads design engineers may utilise findings in this work to look at designing rubber rail pads that will sufficiently damp excessive rail vibrations. Railway engineers may utilise findings in this work to look at different mechanisms that may be affected on railway train wheels to ultimately suppress excessive vibration. The HDPE and Hytrel/6358 rubber rail pads present different characteristics in the same environment. In the vertical direction, for mid-span rail excitation, the rail on the Hytrel/6358 pad experiences antiresonance vibration around $150 \mathrm{~Hz}$. However, the opposite occurs when the force is applied on top of sleeper point. For the rail on HDPE rail pad, this antiresonance is experienced when either position is excited, more in particular in the frequency range of $250-300 \mathrm{~Hz}$. In the horizontal direction, rails on both types of rubber rail pads vibrate at resonance, particularly in the frequency range of $400-500 \mathrm{~Hz}$. At lower frequencies below $300 \mathrm{~Hz}$, rails vibrate with antiresonance in the vertical direction. The first order axle bending; and the first and second order wheel bending modes are found to be of significance. There is a significant need of tuned wheelset vibration dampers for the wheelset used by the D39200 locomotives in the lines. One damper shall be tuned to damp resonance modes along the wheelset axle, whilst the other shall be applied around the wheel web of the gear-side wheel. 


\section{References:}

1. B. M. Balekwa, Masters Dissertation: Corrugation Wavelength Fixing Mechanism and its Relationship to Train and Track Geometry Parameters, Johannesburg: University of Johannesburg, (2017).

2. S. L. Grassie and J. Kalousek, "Rail Corrugation: Characteristics, Causes and Treatments," Part F: J. Rail. Rapid. Trans, pp. 57 - 68, 207 (1993).

3. J. Han, X. Xiao, Y. Wu, Z. Wen and G. Zhao, "Effect of Rail Corrugation on Metro Interior Noise and its Control," App. Acous, https://doi.org/10.1016/j.apacoust.2017.09.007, pp. 63 - 70, 130 (2018).

4. X. Cui, Z. Cheng, Z. Yang, B. Huang and Z. Du, "Study on the Phenomenon of Rail Corrugation on High-Speed Rail Based on the Friction-Induced Vibration and Feedback Vibration," International Journal of Vehicle Mechanics and Mobility, DOI: 10.1080/00423114.2020.1817507, (2020).

5. X. Zhao, P. Zhang and Z. Wen, "On the Coupling of the Vertical, Lateral and Longitudinal Wheel-Rail Interactions at High Frequencies and the Resulting Irregular Wear," Wear, Vols. 430 - 431, https://doi.org/10.1016/j.wear.2019.05.017, pp. 317 326, (2019).

6. W. Cai, M. Chi, P. Shackleton, D. Crosbee and Y. Zhao, "Experimental and Numerical Investigation into Formation of Metro Wheel Polygonization," Shock and Vibration, Article ID 1538273, https://doi.org/10.1155/2019/1538273, (2019).

7. S. Grassie and J. Kalousek, "Rail Corrugation: Causes and Cures," Wheel-Rail Technology, pp. 24 - 26, July, (2000).

8. D. T. Eadie, J. Kalousek and K. C. Chiddick, "The Role of High Positive Friction Modifier in the Control of Short Pitch Corrugations and Related Phenomena," Wear, 253, pp. 185 - 192, 1 (2000).

9. T. Xin, S. Wang, L. Gao, H. Huo, Y. Ding, P. wang, P. Chen and P. Liu, "Field Measurement of Rail Corrugation Influence on Environmental Noise and Vibration: A Case Study in China," Measurement, ISSN 0263-2241, p. https://doi.org/10.1016/j.measurement.2020.108084, 164 (2020).

10. K. Alten and A. Fuchs, "Detecting and Classifying Rail Corrugation Based on Axle Bearing Vibration," International Conference on Acoustics, Speech and Signal Processing (ICASSP), DOI: 10.1109/ICASSP.2019.8683317, 12 - 17 May, (2019).

11. D. Wei , X. Wei, Y. Liu , L. Jia and W. Zhang, "The Identification and Assessment of Rail Corrugation Based on Computer Vision," App. Sci, no 18, p. https://doi.org/10.3390/app9183913, 9 (2019).

12. C. Dong, Q. Mao, X. Ren, D. Kou, J. Qin and W. Hu, "Algorithms and Instrument for Rapid Detection of Rail Surface Defects and Vertical Short-Wave Irregularities Based on FOG and Odometer," IEEE Access, doi: 10.1109/ACCESS.2019.2903488, pp. 31558 - 31572, 7 (2019).

13. B. M. Balekwa, A. Mashamba and D. Kallon, "Application of Modal Analysis to Establish the Wavelength Fixing Mechanism for Rail Corrugation," Proceedings of the 11th SACAM, pp. 212 - 223, (2018).

14. B. Balekwa, D. V. V. Kallon and D. J. Fourie, "Vibration Response for class D44 and D39 200 Locomotive Wheelsets due to Dynamic Loads Excitation," Proceedings of OIC 2019, pp. 418 - 421, 2 - 4 October, (2019). 
15. Indianmart, "Studded Rail Rubber Pads, Railway, Railroad, Train Components," Indianmart, [Online]. Available: https://www.indiamart.com/proddetail/studded-railrubber-pads-10501823362.html. [Accessed 05 October 2018].

16. D. J. Thompson, Railway Noise and Vibration Handbook: Mechanisms, Modelling and means of Control, Oxford: Elsevier, (2009).

17. B. Balekwa, D. V. V. Kallon and D. J. Fourie, "Vertical and Horizontal Vibration Response for Corrugated Track Curves Supported on Steel and PY-Type Concrete Sleepers," Proceedings of OIC 2019, pp. 474 - 482, 2-4 October, (2019).

18. B. Balekwa and D. V. V. Kallon, "Correlation of Short Pitch Rail Corrugation with Railway Wheel-Track Resonance at Low Frequencies of Excitation," Vibration, no 4, pp. 491 - 520, 3 (2020).

19. E. Articles, "Engineering Articles," [Online]. Available:

http://www.engineeringarticles.org/what-is-ballast-railway-ballast-functions-of-ballast/. [Accessed 05 October 2018], 20 May, (2015).

20. J. Ali Zakeri and S. Ali Mosayebi, "Study of Ballast Layer Stiffness in Railway Tracks," Gradevinar. DOI: 10.14256/JCE.1232.2015, no 68, pp. 311 - 318, 4 (2016).

21. X. Sheng, C. Zhao, P. Wang and D. Liu, "Study on Transmission Characteristics of Vertical Rail Vibrations in Ballast Track," Mathematical Problems in Engineering, pp. 13 pages, Article ID 5872419, https://doi.org/10.1155/2017/5872419, 19 December, (2017).

22. X. Song, Y. Qian, K. Wang and P. Liu, "Effect of Rail Pad Stiffness on Vehicle-Track Dynamic Interaction Excited by Rail Corrugation in Metro," Journal of the Transportation Research Board, no 6, pp. 225 - 243, 2674 (2020). 